\title{
Inverted "T" incision restricted to lower uterine segment as a new surgical technique during caesarean section with previous caesarean scaring
}

\begin{abstract}
Background: Cesarean section (CS) rates have been increasing worldwide. Many complications may arise during uterine entry in patients with previous CS due to scarring and loss of lower segment elasticity hence the need for development of a safer surgical technique.
\end{abstract}

Objectives: to evaluate a new surgical technique of uterine entry during CS through elective inverted $\mathrm{T}$ incision in lower uterine segment (LUS) in patients with repeated cesarean section/s.

Setting: Obstetrics \& Gynecology Department of Al Azhar University Hospital.

Patients and methods: A total of 120 term cephalic singleton pregnant women with previous cesarean section/s were randomized in to 2 groups.

Group A: 60patients for whom elective CS with the new technique of Inverted T lower segment CS (LSCS) was performed.

Group B: 60patients for whom curvilinear LSCS was performed.

Results: Elective inverted $\mathrm{T}$ incision was associated significantly with decrease incidence of angles extension, broad ligament hematoma and injury of LUS (1.7\% vs. $11.7 \% \mathrm{p}=0.028),(0.0 \%$ vs. $6.7 \% \mathrm{p}=0.042)$ and $(0.0 \%$ vs. $6.7 \% \mathrm{p}=0.042)$ for group A \& $\mathrm{B}$ respectively. At the start of the study it was associated significantly with increased amount of blood loss and longer duration of CS $(495.7 \pm 47.9 \mathrm{cc}$ vs. $417.4 \pm 34.9 \mathrm{cc}$, and $47.6 \pm 5.5$ Vs. $38.97 \pm 4.1$ minutes $\mathrm{p}=0.001$ for A \& B respectively), however by study progression the difference become statistically insignificant $(p=0.058)$. The new technique did not increase incision- delivery interval or fetal morbidity $(\mathrm{p}>0.05)$.

Conclusion: Our new technique of inverted " $T$ " incision restricted to LUS during Elective CS significantly decreased the incidence of angles extension, broad ligament hematoma and lower segment injury. It avoids upper segment and lateral extension without affection of operation time or blood loss. It is a safer technique for mother and fetus in scared LUS due to repeated CS.

Keywords: inverted " $\mathrm{T}$ " incision, elective cesarean section, lower uterine segment, repeated cesarean section
Volume 2 Issue 5 - 2016

\author{
Ahmed Ali M Nasr \\ Department of Obstetrics and Gynecology, Egypt
}

Correspondence: Ahmed Ali M Nasr, Assistant Professor of Obstetrics and Gynecology-Al Azhar University- Assiut- Egypt, Tel 00201224204420,Email Aam_Nasr@Yahoo.Com

Received: July 16, 2016 | Published: September 23, 2016
Abbreviations: CS, caesarean section; LSCS, lower segment cesarean section; USCS, upper segment caesarean section; LUS, lower uterine segment; UUS, upper uterine segment; WHO, world health organization; EDHS, egypt demographic and health survey

\section{Introduction}

A caesarean section (CS) is a life-saving surgical procedure when certain complications arise during pregnancy and labor. However, it is a major surgery and is associated with immediate maternal and perinatal risks and may have implications for future pregnancies as well as long-term effects still being investigated. ${ }^{1} \mathrm{CS}$ rates have been increasing worldwide to as high as 25 to $30 \%$, and are a growing concern in many countries. High rates of cesarean deliveries are now an international phenomenon. ${ }^{2}$ According to Egypt Demographic and Health Survey (EDHS) 2014on the frequency of caesarean sections, more than one-half of deliveries in the five-year period before the survey were by caesarean section. The likelihood of a caesarean delivery increased with the age of the mother and decreased with the child's birth order. Caesarean deliveries were more common in urban areas than in rural areas (60percent and 48percent, respectively). ${ }^{3}$ A cesarean section as a surgical procedure can lead to numerous complications in both mother and child. A WHO study of adverse maternal and fetal outcomes between 2004 and 2008 in 24 countries showed that cesarean sections are associated with increased risks for mother and child, and that therefore a cesarean section should only be performed when clear advantages are to be gained. ${ }^{4}$ There are many possible ways of performing a cesarean section. A study of obstetricians in the UK found a wide variation in techniques. ${ }^{5}$ The techniques used may depend on many factors including the clinical situation and the preferences of the operator. ${ }^{6,7}$ Many complications may arise especially during uterine entry in patients with previous CS due to scarring at the incision site and loss of lower segment elasticity hence the need for evaluation of safer surgical techniques. The aim of this study was to evaluate a new surgical technique of uterine entry during elective CS through inverted T incision restricted 
to LUS in patients with one or more prior cesarean section/s as regard to duration of the procedure, amount of blood loss, angles extension, broad ligament hematoma, lower and upper segment extensions, bladder injury and fetal outcome

\section{Patients and methods}

A total of 120pregnant women attending Obstetrics and Gynecology department of Al-Azhar University Hospital were included in this study. Data collection, surgical procedure and intraoperative observations were performed by the same operator for all patients.

\section{Inclusion criteria}

Maternal: women aged 20-35years old, previous 1-3 C.S, free of medical disorders, normal coagulation profile and elective C.S.

Fetal: Singleton pregnancy, cephalic presentation, gestational age 37-40weeks, the study was approved by Ethical Committee of Al-Azhar University. A written consent was obtained from all participants after explaining procedures to patients before enrollment. After proper history taking, general, abdominal, local examination and investigations patients were randomized into 2 equal groups using a computer program for randomization.

Group (A): 60 patients for whom Inverted $\mathrm{T}$ incision restricted to LUS was performed (Study group).

Group (B): 60 patients for whom curvilinear LSCS of the uterus was performed (control group).

Method: After proper sterilization, toweling, catheterization, incision of the skin and subcutaneous tissue through Pfannenstiel incision, opening of rectus sheath and separation of recti muscles, opening of parietal peritoneum and development of bladder flap as usual, followed by uterine incision as follow:

Group (A): Opening of the uterus by Inverted $\mathrm{T}$ incision restricted only to the LUS. The transverse limb of T incision was done $2-3 \mathrm{~cm}$ above the upper edge of the uterovesical fold of peritoneum and extended laterally using either blunt dissection with the fingers or scissors. The vertical limb of $\mathrm{T}$ incision was then made sharply with the scalpel in the midline $1-3 \mathrm{~cm}$ without extension to the upper segment and deep to the level of the fetal membranes, with care being made not to incise the membranes, The fetal membranes are to be left intact at this stage in order to facilitate the vertical mid line incision without fetal injury and to maintain the liquor until the uterine incision is completed (Figures 1-4).

Group (B): opening of the lower uterine segment by the traditional transverse curvilinear incision previously mentioned by Dahlke et al. ${ }^{8}$ The incision was made sharply with the scalpel in the midline and deep to the level of the fetal membranes, and extended laterally using either blunt dissection with the fingers or scissors.

Fetal extraction was performed as usual in both groups. Closure of uterine incision was performed using vicryl 0 or 1 as follow:

i. For Group (A): closure of the vertical incision is performed first as a separate incision in 2layers then closure of the transverse incision in 2layers (Figures 5) (Figure 6).

ii. For Group (B): closure of the transverse incision in 2 layers as described by Dahlke et al. ${ }^{8}$
After uterine closure, the parietal peritoneum, recti muscles, rectus sheath were closed as usual, closure of subcutaneous tissue and skin in subcuticular manner.

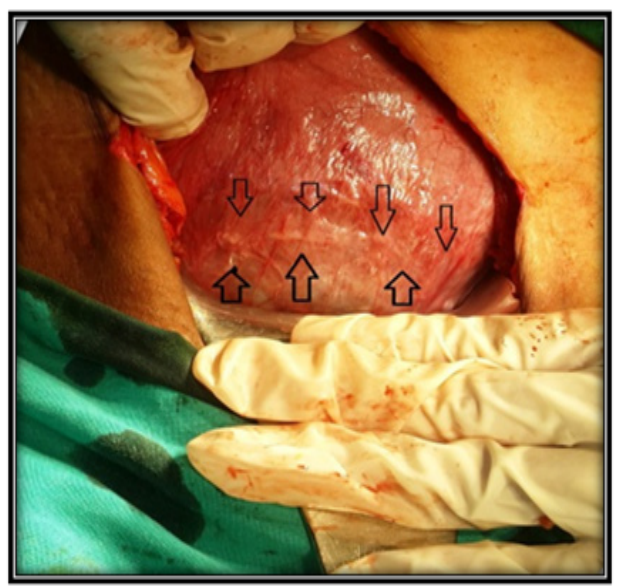

Figure I Gravid uterus with visible scar in LUS (arrows) before uterine incision.

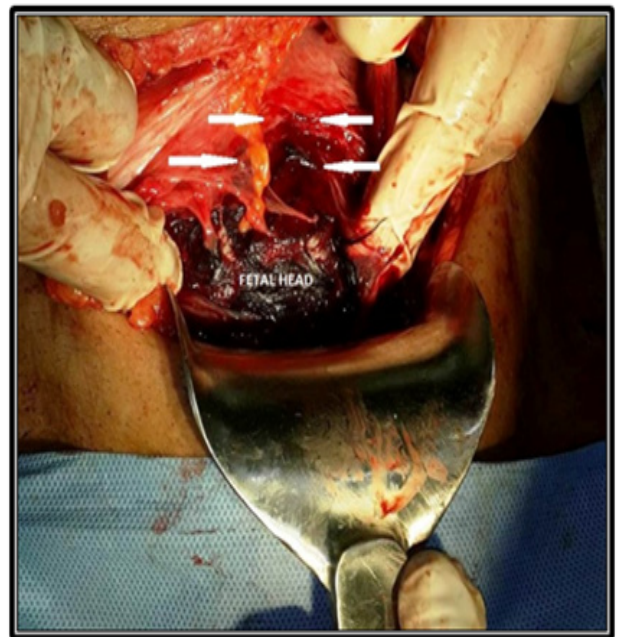

Figure 2 Visible fetal head before extraction after inverted $\mathrm{T}$ (arrows) restricted to LUS.

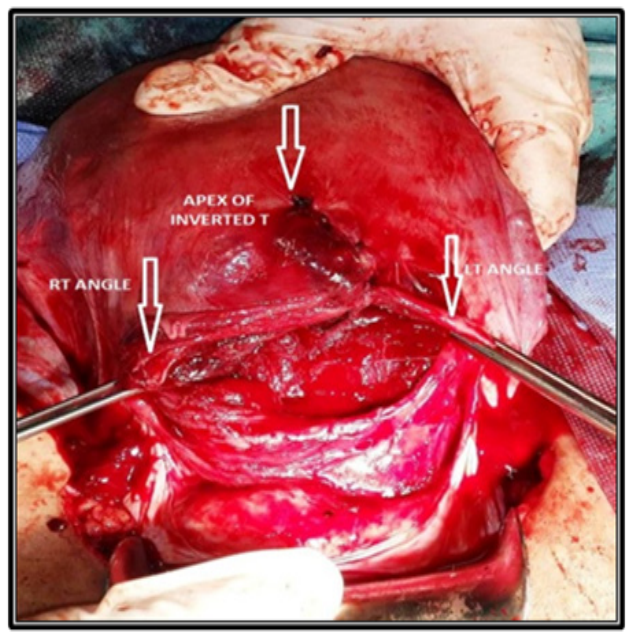

Figure 3 Shape of the uterus after fetal extraction shows apex, Rt\& Lt angles of incision. 


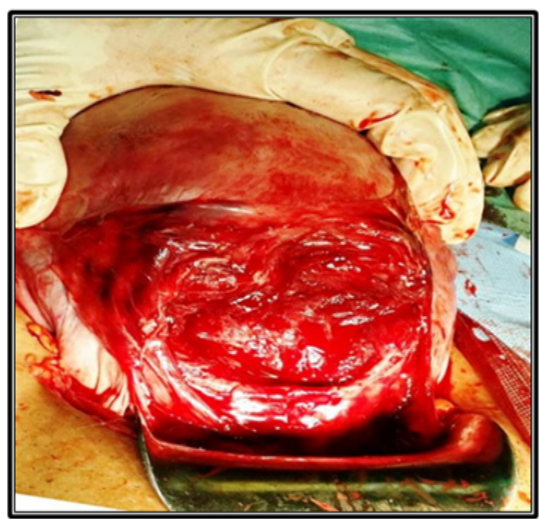

Figure 4 Shape of the uterus after fetal extraction (exteriorized).

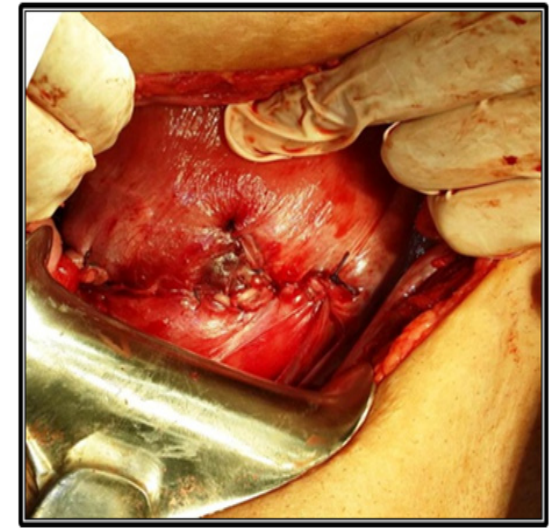

Figure $\mathbf{5}$ Shape of the uterus after closure of inverted T incision in LUT.

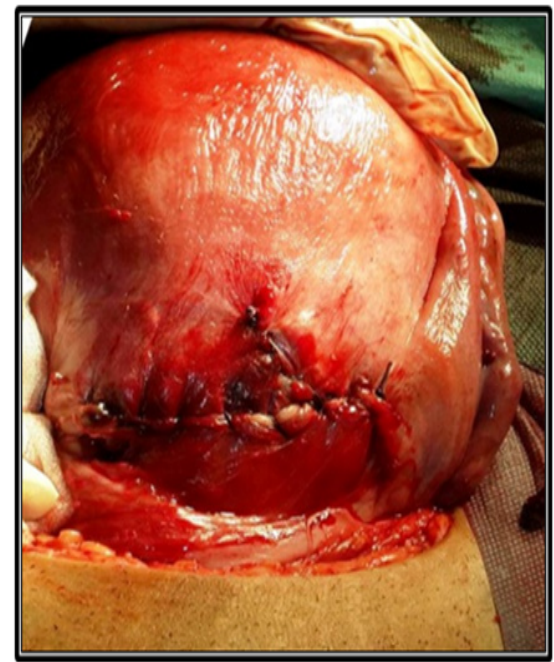

Figure 6 Shape of the uterus (exterionrized) after closure of inverted T.

\section{Intra operative observation for mother and fetus for}

Duration of the whole operation, Incision-Delivery Interval (minutes) and amount of blood loss (cc)

i. Estimated roughly by weighing the towels and gauze before and after operation

ii. Angles extension, broad ligament hematoma and injury to the bladder or ureter iii. Injury to the lower flap of LUS, extension to the upper segment

iv. Fetal assessment for APGAR score at $1 \& 5$ minutes, NICU admission and fetal injury

\section{Statistical analysis}

Data was analyzed using Statistical Package for Social Science (SPSS) version 22. Qualitative data, quantitative data, frequency, mean, standard deviation (SD), and percent distribution were calculated. Chi square and $t$ test were used to compare groups. $\mathrm{p}<0.05$ was considered as the level of significance.

\section{Results}

A total of 120 term singleton cephalic pregnant women were randomized into two equal groups according to technique of uterine incision into: Study group (A) for whom elective CS through an inverted $\mathrm{T}$ incision restricted to the LUS was done and control group (B) for whom elective CS through the traditional curvilinear incision of the LUS was done. Table 1 shows socio-demographic and clinical characteristics of both groups. Table 2 shows operative finding for both groups as regard to total duration of CS, incisiondelivery interval, and amount of blood loss. Table 3 shows operative finding for subgroups (former and later subgroups, 30patients for each) depending on which patients were operated upon first. Table 4 shows comparison between both groups as regard to intraoperative complications. Table 5 shows comparison between groups according to fetal outcome.

Table I Socio-demographic \&clinical characteristics of the study groups

\begin{tabular}{|c|c|c|c|}
\hline & $\begin{array}{l}\text { Group A } \\
(n=60)\end{array}$ & $\begin{array}{l}\text { Group B } \\
(n=60)\end{array}$ & P. value \\
\hline Age(year) mean+SD & $25.6 \pm 3.8$ & $25.7 \pm 4.2$ & 0.908 \\
\hline \multicolumn{4}{|l|}{ Social class } \\
\hline Low & $42(70 \%)$ & $44(73.3 \%)$ & \multirow{2}{*}{0.839} \\
\hline High & $18(30 \%)$ & $16(26.7 \%)$ & \\
\hline \multicolumn{4}{|l|}{ Educational level } \\
\hline Illiterate & $35(58.3 \%)$ & $36(60 \%)$ & \multirow{3}{*}{0.901} \\
\hline Primary \& secondary & $20(33.3 \%)$ & $18(30 \%)$ & \\
\hline Higher education & $5(8.3 \%)$ & $6(10 \%)$ & \\
\hline \multicolumn{4}{|l|}{ Residence } \\
\hline Rural & $44(73.3 \%)$ & $47(78.3 \%)$ & \multirow{2}{*}{0.92} \\
\hline Urban & $16(26.7 \%)$ & $13(2 \mid .7 \%)$ & \\
\hline \multicolumn{4}{|c|}{ Gestational age (weeks) } \\
\hline Range & $37-40$ & $37-40$ & - \\
\hline Mean +SD & $38 \pm 3.7$ & $38 \pm 4.2$ & 0.334 \\
\hline $\mathrm{BMI} \mathrm{kg} / \mathrm{m}^{2}($ mean $\pm \mathrm{SD})$ & $21.4 \pm 1.7$ & $22.2 \pm 2.6$ & 0.059 \\
\hline \multicolumn{4}{|l|}{ Previous CS } \\
\hline Previous ICS & $28(46.7 \%)$ & $27(45 \%)$ & \\
\hline Prev2CS & $21(35 \%)$ & $22(36.7 \%)$ & 0.979 \\
\hline Prev3CS & II(I8.3\%) & II(I8.3\%) & \\
\hline
\end{tabular}

BMI, body mass index. CS, caesarean section; SD, standard deviation 
Table 2 Comparison between groups according to operative findings

\begin{tabular}{llll}
\hline & $\begin{array}{l}\text { Group A } \\
(\mathbf{n}=60)\end{array}$ & $\begin{array}{l}\text { Group B } \\
(\mathbf{n}=60)\end{array}$ & P. value \\
\hline $\begin{array}{l}\text { Total duration of CS } \\
\text { (minutes) }\end{array}$ & $47.6 \pm 5.5$ & $38.97 \pm 4.1$ & $0.00 \mathrm{I}$ \\
$\begin{array}{l}\text { Incision-delivery } \\
\text { interval (minutes) }\end{array}$ & $5.0 \pm 0.43$ & $4.9 \pm 0.45$ & 0.216 \\
$\begin{array}{l}\text { Blood Loss (cc) } \\
\text { M }\end{array}$ & $495.7 \pm 47.9$ & $417.4 \pm 34.9$ & 0.001 \\
\hline
\end{tabular}

Values are given as mean $\pm \mathrm{SD} ; \mathrm{CS}$, caesarean section.

Table 3 Operative findings in former and later subgroups

\begin{tabular}{|c|c|c|c|}
\hline & $\begin{array}{c}\text { Group (A) } \\
\text { Mean } \pm \text { SD }\end{array}$ & $\begin{array}{c}\text { Group (B) } \\
\text { Mean } \pm \text { SD }\end{array}$ & P. value \\
\hline \multicolumn{4}{|c|}{ Duration of CS (minutes) } \\
\hline Former subgroup $(n=30)$ & $53.5 \pm 5$ & $39.7 \pm 4.8$ & 0.001 \\
\hline Later subgroup $(n=30)$ & $40.4 \pm 7.8$ & $38.4 \pm 2.2$ & 0.058 \\
\hline \multicolumn{4}{|c|}{ Incision-delivery interval } \\
\hline Former subgroup $(n=30)$ & $6.0 \pm 0.41$ & $5.9 \pm 0.46$ & 0.211 \\
\hline Later subgroup $(\mathrm{n}=30)$ & $4.7 \pm 0.51$ & $4.5 \pm 0.66$ & 0.066 \\
\hline \multicolumn{4}{|l|}{ Blood Loss (ml) } \\
\hline Former subgroup $(n=30)$ & $566.2 \pm 48.7$ & $421.3 \pm 43.7$ & 0.001 \\
\hline Later subgroup $(n=30)$ & $430.2 \pm 50.2$ & $416.3 \pm 25.1$ & 0.058 \\
\hline
\end{tabular}

Table 4 Comparison between groups according to intraoperative complications

\begin{tabular}{|c|c|c|c|c|c|c|}
\hline & & \multicolumn{2}{|c|}{$\begin{array}{l}\text { Group A } \\
(n=60)\end{array}$} & \multicolumn{2}{|c|}{$\begin{array}{l}\text { Group B } \\
(n=60)\end{array}$} & \multirow[t]{2}{*}{ P. value } \\
\hline & & no. & $\%$ & no. & $\%$ & \\
\hline \multirow{3}{*}{ Angles Extension } & Yes & I & 1.7 & 7 & 11.7 & 0.028 \\
\hline & & & & & & \\
\hline & No & 59 & 98.3 & 53 & 88.3 & \\
\hline \multirow{2}{*}{$\begin{array}{l}\text { Broad Ligament } \\
\text { Hematoma }\end{array}$} & Yes & 0 & 0 & 4 & 6.7 & 0.042 \\
\hline & No & 60 & 100 & 56 & 93.3 & \\
\hline \multirow{3}{*}{ Bladder Injury } & Yes & 0 & 0 & 0 & 0 & - \\
\hline & & & & & & \\
\hline & No & 60 & 100 & 60 & 100 & \\
\hline \multirow{2}{*}{$\begin{array}{l}\text { Upper segment } \\
\text { Injury }\end{array}$} & Yes & 0 & 0 & 0 & 0 & - \\
\hline & No & 60 & 100 & 60 & 100 & \\
\hline \multirow{2}{*}{$\begin{array}{l}\text { Lower segment } \\
\text { Injury }\end{array}$} & Yes & 0 & 0 & 4 & 6.7 & 0.042 \\
\hline & No & 60 & 100 & 56 & 93.3 & \\
\hline
\end{tabular}

Table 5 Comparison between groups according To fetal outcome

\begin{tabular}{lllll}
\hline & & $\begin{array}{l}\text { Group A } \\
(\mathbf{n = 6 0 )}\end{array}$ & $\begin{array}{l}\text { Group B } \\
(\mathbf{n = 6 0 )}\end{array}$ & P. value \\
\hline APGAR score & I min & $7.8 \pm 0.7$ & $7.7 \pm 0.6$ & 0.403 \\
NICU & $5 \mathrm{~min}$ & $8.2 \pm 0.4$ & $8.1 \pm 0.5$ & 0.229 \\
admission & Yes & $\mathrm{I}(1.7 \%)$ & $\mathrm{I}(\mathrm{I} .7 \%)$ & $\mathrm{I}$ \\
Fetal injury & No & $59(98.3 \%)$ & $59(98.3 \%)$ & \\
\hline
\end{tabular}

NICU, neonatal intensive care unit.

\section{Discussion}

Caesarean section is a common major operation performed on women in the world. There are many possible ways of performing a caesarean section. Operation and operative techniques vary depending on the clinical situation and surgeon preferences. Safe delivery is important for mother and infant. Any potential reduction of birth trauma to the infant has to be balanced against increased illhealth for the mother. ${ }^{9}$ This is a prospective randomized controlled study performed on a total of 120 pregnant patients with one or more previous cesarean section $\backslash$ s. patients were randomized in to two groups, 60patients for whom inverted T-LSCS was performed (group A), and another60patients for whom transverse lower segment curvilinear incision of the uterus was performed (group B). All CS were elective. Statistically significant difference was found between both groups as regard to socio-demographic and clinical characteristics. In the present study the incision-delivery interval was comparable for both groups with no statistically significant difference $(\mathrm{p}=0.216)$. In the present study bladder injury and upper uterine segment injury did not occur in either group. This finding may be due to the fact that all cesarean sections in our study were elective and well planned. In accordance with our results Rahman et al., ${ }^{10}$ on their retrospective study on 7,708 cesarean deliveries found no correlation between bladder injury and the type of uterine incision.

In the present study it was found that inverted $\mathrm{T}$ uterine incision (group A) was associated significantly with increased amount of blood loss and longer duration of CS compared to the curvilinear uterine incision (group B) (Mean blood loss was $495.7 \pm 47.9 \mathrm{cc}$ vs. $417.4 \pm 34.9 \mathrm{cc}, \mathrm{p}=0.001$ and mean duration of CS was $47.6 \pm 5.5 \mathrm{Vs}$. $38.97 \pm 4.1$ minutes $\mathrm{p}=0.001$ for group $\mathrm{A}$ and $\mathrm{B}$ respectively). These result were in accordance with Boyle et al., ${ }^{11}$ who found that extension of the low transverse incision by creating a low vertical incision in the midline (inverted T) or a vertical incision at the lateral aspect of the uterine incision (J extension) were associated with increased incidence of maternal blood loss, and uterine artery laceration compared with low-segment transverse incision without extension. However Boyle et al., ${ }^{11}$ perform T or J extension in upper uterine segment which is more vascular because of myometrial elements that increase the amount of blood loss. During our study and by progression of time, it was noted that duration of CS \& blood loss were decreasing significantly, so we studied patients of each group after rearrangement of them into to 2 subgroups (former subgroup $=30$ patient for whom CS was performed first and later subgroup $=30$ patient for whom CS was performed later after the former one, we found that in former subgroup (A), total duration of CS was longer and amount of blood loss was higher compared to former subgroup (B) and the difference was statistically 
significant ( $\mathrm{p}=0.001$ ), while in later subgroup (A) the difference was not statistically significant as regard to the same parameters $(\mathrm{p}=0.058)$. Results of our study were explained by the gained experience by time and training of the operator on the newer technique with shortening of operation time by repetition of the maneuver that resulted in improvement in duration of cesarean section and reduction of amount of blood loss in the last 30 patients.

In the present study we found that elective inverted $\mathrm{T}$ uterine incision in LUS (group A) was associated significantly with decreased incidence of angles extension, broad ligament hematoma and injury of lower flap of lower uterine segment $(1.7 \%$ vs. $11.7 \% \mathrm{p}=0.028),(0.0 \%$ vs. $6.7 \% \mathrm{p}=0.042)$ and $(0.0 \%$ vs. $6.7 \% \mathrm{p}=0.042)$ for group $\mathrm{A}$ and group $\mathrm{B}$ respectively. These results were against Patterson et al. ${ }^{12}$ who reviewed A 19-years study of a perinatal database and the relevant charts to determine the maternal and perinatal morbidity (puerperal infection, blood loss and blood transfusion, incision extension, injury of pelvic organs and hysterectomy) and maternal mortality associating the low transverse incision, classic CS, and inverted " $\mathrm{T}$ " CS, from1980 to 1998. They found that Classic CS had a higher maternal and perinatal morbidity than inverted T CS and much higher than low transverse CS. However there was no increased maternal or perinatal morbidity if an attempt of low transverse incision had to be converted to an inverted " $\mathrm{T}$ " incision compared to performing a classic CS.

Also our results were against the study done by Boyle et al., ${ }^{11}$ they reviewed the medical records of 56patients delivered between January 1988 and November 1994 by low transverse cesarean birth requiring vertical extension of the incision into-the upper uterine segment. Cases of extension were compared with controls matched for gestational age, presentation, and indication for cesarean delivery. According to the incidence of traumatic complications they found that inverted $\mathrm{T}$ and $\mathrm{J}$ extensions are often associated with intraoperative complications and prolonged hospital stays compared with controls. In accordance with our results Marcyniak ${ }^{13}$ in their study found that blood loss and complications during puerperium didn't differ between both groups, he stated that ' $T$ ' extensions are safe and are not associated with prolonged hospital stays compared with controls. As regard to fetal outcome no statistically significant differences were found between both groups as regard to APGAR score and NICU admission in our study $(\mathrm{p}>0.050)$. Also in our study there were no cases of fetal injury in any of the studied groups. This finding is in accordance with Luthra ${ }^{14}$ in their retrospective cohort study of singleton cesarean deliveries from 2002 to 2009, they observed no difference in neonatal complications between vertical and transverse incision. However in contrary to our results Alexander et al. ${ }^{15}$ in a prospective cohort study conducted in 13 university hospitals to describe the fetal outcome in women undergoing CS. A total of 37,110 cesarean deliveries were included in the registry and $418(1.1 \%)$ had an identified fetal injury. The most common injury was skin laceration $(n=272,0.7 \%)$. They found that the type of uterine incision was associated with fetal injury $3.4 \%$ for " $T$ " or "J" incision, $1.4 \%$ for vertical incision, and $1.1 \%$ for a low transverse incision $(\mathrm{P}=0.003)$. Those results were different from the results of the present study; the difference might be explained by the situation during performing the vertical limb of uterine incision. When comparing our results with the past studies we were faced by a major obstacle that all studies conducted on inverted $\mathrm{T}$ or $\mathrm{J}$ extension of the incision of the uterus during CS were extended to the upper uterine segment (UUS) and almost always during emergency situations as difficult fetal extraction or male presentation. But this was not the situation in the present study because to the best of our knowledge our technique of inverted $\mathrm{T}$ procedure was the first to evaluate inverted $\mathrm{T}$ incision performed completely. In LUS without extension to UUS. Also in this study CS was strictly elective not emergency, the fetal presentation was cephalic \&CS was performed on patients with previous cesarean section/s and planned mainly to protect the tissues from any excessive damage especially UUS, LUS, uterine vessels, broad ligament, urinary bladder and the fetus.

\section{Limitation of the study}

However our study was deficient as regard to post-operative follow up to evaluate post-operative hospital stay, the need for analgesics, puerperal infection and effect on next pregnancies.

\section{Conclusion}

Elective LSCS through inverted $\mathrm{T}$ incision of the uterus significantly decreased the incidence of angles extension, broad ligament hematoma and lower segment injury. It avoids upper and lower uterine segment extension without elongation of operation time or increasing blood loss. It is a safer method for mother and fetus in patient with scared lower uterine segment due to previous CS.

\section{Acknowledgements}

None.

\section{Conflict of interest}

The author declares no conflict of interest.

\section{References}

1. Betrán AP, Ye J, Moller AB, et al. The Increasing Trend in Caesarean Section Rates: Global, Regional and National Estimates: 1990-2014. PLoS One. 2016;11(2):e0148343

2. Khawaja M, Jurdi R, Kabakian-Khasholian T. Rising trends in cesarean section rates in egypt. Birth. 2004;31(1):12-16.

3. Egypt Demographic and Health Survey 2014. Egypt: Ministry of health and population Cairo; 2014. p. 1-52

4. Souza JP, Gülmezoglu A, Lumbiganon P, et al. Caesarean section without medical indications is associated with an increased risk of adverse short-term maternal outcomes: the 2004-2008 WHO global survey on maternal and perinatal health. BMC Med. 2010;8:71.

5. Tully L, Gates S, Brocklehurst P, et al. Surgical techniques used during caesarean section operations: results of a national survey of practice in the UK. Eur J Obstet Gynecol Reprod Biol. 2002;102(2):120-126.

6. Bamigboye AA, Hofmeyr GJ. Closure versus non $\square$ closure of the peritoneum at caesarean section. Cochrane Database Syst Rev. 2003;4:CD000163

7. Boyle JG, Gabbe SG. T and J vertical extensions in low transverse caesarian births. Obstet Gynecol. 1996;87(2):238-243.

8. Dahlke JD, Mendez-Figueroa H, Rouse DJ, et al. Evidence-based surgery for cesarean delivery: an updated systematic review. Am J Obstet Gynecol. 2013;209(4):294-306.

9. Dodd JM, Anderson ER, Gates S. Surgical techniques for uterine incision and uterine closure at the time of caesarean section. Cochrane Database Syst Rev. 2008;3:CD004732.

10. Rahman MS, Gasem T, Al Suleiman SA, Aet al. Bladder injuries during cesarean section in a University Hospital: a 25-year review. Arch Gynecol Obstet. 2009;279(3):349-352. 
11. Boyle JG, Gabbe SG. T and J vertical extensions in low transverse cesarean births. Obstet Gynecol. 1996;87(2):238-243.

12. Patterson LS, O'Connell CM, Baskett TF. Maternal and perinatal morbidity associated with classic and inverted T cesarean incisions. Obstet Gynecol. 2002;100(4):633-637.

13. Marcyniak M, Herlenius D, Hamela A, et al. T-vertical extension of the uterus in cesarean section. Ginekol Pol. 2000;71(7):611-617.
14. Luthra G, Gawade P, Starikov R, et al. Uterine incision-to-delivery interval and perinatal outcomes in transverse versus vertical incisions in preterm cesarean deliveries. J Matern Fetal Neonatal Med. 2013;26(18):1788-1791.

15. Alexander JM, Leveno KJ, Hauth J, et al. Fetal injury associated with cesarean delivery. Obstet Gynecol. 2006;108(4):885-890. 